\title{
Örgüt Kültürünün ve Örgütsel Adaletin Bilgi Paylaşımı Üzerine Etkisi: Bir Devlet Üniversitesi Örneği ${ }^{1}$
} (Araştırma Makalesi)

The Effect of Organizational Culture and Organizational Justice on Knowledge Sharing: Sample of a State University

Doi: 10.29023/alanyaakademik.492117

\section{Faruk Kerem ŞENTÜRK}

Dr. Öğr. Üyesi, Düzce Üniversitesi, İsletme Fakültesi, Issletme Bölümü, keremsenturk@duzce.edu.tr

Orcid No: 0000-0002-3055-0797

\section{Yasin CARMAN}

Düzce Üniversitesi, Sosyal Bilimler Enstitüsü, Işsletme ABD, carman_yasin@hotmail.com Orcid No: 0000-0003-2776-7714

Bu makaleye atıfta bulunmak için: Şentürk, F.K., Carman, Y. (2019). Örgüt Kültürünün ve Örgütsel Adaletin Bilgi Paylaşımı Üzerine Etkisi: Bir Devlet Üniversitesi Örneği. Alanya Akademik Bakış, 3(1), 1-18.

\begin{tabular}{|c|c|}
\hline & ÖZET \\
\hline Anahtar kelimeler: & $\begin{array}{l}\text { Bu çalışmanın temel amacı, örgütlerdeki kültür tipleri ile adalet algılarının } \\
\text { bilgi paylaşımı niyetine ve bilgi paylaşım niyetinin bilgi paylaşma tutumu }\end{array}$ \\
\hline $\begin{array}{l}\text { Örgüt Kültürü, } \\
\text { Örgütsel Adalet, } \\
\text { Bilgi Paylaşımı }\end{array}$ & $\begin{array}{l}\text { üzerine etkisini belirlemektir. Araştırmada nicel araştırma yöntemi } \\
\text { kullanılmış ve araştırma verileri anket tekniği ile toplanmıştır. Araştırmanın } \\
\text { evrenini Düzce Üniversitesi akademik ve idari personeli oluşturmaktadır. } \\
\text { Düzce Üniversitesi Personel Daire Başkanlığından elde edilen verilere göre }\end{array}$ \\
\hline $\begin{array}{l}\text { Makale Geliş Tarihi: } \\
\text { 04.12.2018 } \\
\text { Kabul Tarihi: } \\
\text { 18.01.2019 }\end{array}$ & $\begin{array}{l}\text { akademik ve idari personel saylsı } 1765 \text { 'tir. Araştırmada } 322 \text { ankete } \\
\text { ulaşılmıştır. Yapılan analizler sonucunda; örgüt kültürü tiplerinden } \\
\text { hiyerarşi kültür tipinin, örgütsel adalet boyutlarından prosedürel adalet } \\
\text { boyutunun bilgi paylaşma niyeti üzerinde etkili olduğu tespit edilmiştir. Son } \\
\text { olarak bilgi paylaşım niyetinin ise bilgi paylaşma tutumu üzerinde pozitif } \\
\text { yönde etkili olduğu saptanmıştır. }\end{array}$ \\
\hline
\end{tabular}

Keywords:

Organizational

Culture

Organizational

Justice

Knowledge Sharing

\begin{abstract}
The main purpose of this study is to determine the effects of culture types and perception of justice of the organization on intention to share knowledge within the organization. Furthermore, it is also aimed to detect the effects of intention of knowledge sharing on attitude toward knowledge sharing. In this research, quantitative research method was used and data were obtained by a questionnaire form. Duzce University academic and administrative staffs constitute universe of the research. According to the data obtained from the academic and administrative staffs, the total number of employees who constituting the population of the research is 1765. 322
\end{abstract}

\footnotetext{
${ }^{1}$ Bu çalışma Düzce Üniversitesi Sosyal Bilimler Enstitüsü İşletme Anabilim Dalı Yüksek Lisans Programı mezunu Yasin CARMAN'ın yüksek lisans tezinden uyarlanmıştır.
} 
surveys were reached in the research. According to the results of the analysis; hierarchy culture type, which is one of the organizational culture types, has the most effect on the intention to share knowledge by comparison other culture types. Also procedural justice, which is one of the dimensions of organizational justice, has effect on the intention to share knowledge when other organizational justice dimension has no effect. Lastly analysis revealed that intention to share knowledge has a positive effect on the attitude toward knowledge sharing.

\section{GIRİŞ}

Örgütsel davranış alanında örgüt kültürü, örgütsel adalet ve bilgi paylaşımı ile ilgili alan yazın incelendiğinde, örgütlerdeki bilgi paylaşım sürecinde örgüt kültürü ve örgütsel adalet kavramlarının karşılıklı etkileşimlerinin göz önünde bulundurulmasının, örgütleri daha etkili hale getirme konusunda önemli bir önkoşul olarak değerlendirildiği görülmektedir. Her örgütü karakterize eden özellikler farklıdır ve bu farklılığın asıl kaynaklarından birisi de örgüt kültürü kavramıdır. Örgütün kendisini gerek çalışanlarına gerek dış paydaşlarına tanıtmasında işletme içinde kullanılan dil, kuralların yoğunluğu, tercih edilen yönetsel yapı, iletişim türü, liderlik tarzı, gerçekleştirilen tören ve seremoniler gibi kültürel bileşenler önem arz etmektedir. Özellikle örgüt içinde adalet algısının kültürün bir parçası haline getirilmesi halinde iletişimin daha açık ve aktif hale gelebileceği ve bilgi paylaşım oranının artacağı öngörülmektedir. Bu bağlamda gerçekleştirilen araştırma kapsamında farklı örgüt kültürü tiplerinin ve adalet algılarının bilgi paylaşımı üzerindeki etkileri araştırılmıştır.

\section{LITERATÜR TARAMASI}

$\mathrm{Bu}$ başlık altında işletmeyi içeriden ve dışarıdan tanımlamada önemli bir unsur olan örgüt kültürü, işletme içindeki işleyişte çalışanların tatmin ve motivasyonlarına temel teşkil eden örgütsel adalet algısı ve günümüz işletmelerinin kaçınılmaz olarak yapmak zorunda oldukları bilgi paylaşımı konuları teorik çerçevede ele alınmaktadır.

\section{1. Örgüt Kültürü}

Sosyal bilimler alanında kültür olgusu ekseriyetle bilgi, inanç ve ananeleri içinde barındıran katılım olarak anılmaktadır. Bu tanımdaki bilgi ve hünerler, toplumu oluşturan üyelere karşı yararlı olmalarıdır. Bundan dolayı kültür, yaşam tarzının sınırlarını belirleyen bir olgu olarak da değerlendirilebilmektedir (Güvenç, 1991: 96).

İşletmeler belli bir ortamda hayatlarını devam ettirmektedirler. Bu ortamdaki bireylerin kendilerine has inanışları, algılama biçimleri ve farklı olaylara karşı farklı davranış kalıpları bulunmaktadır. İşletme açısından ortama ait kültürel algıyı anlamak son derece önemlidir. Fakat bir rekabet ortamı içinde faaliyetlerini devam ettiren işletmeyi, o ortamın nicelik ve nitelikleri, yasaları, çağın teknolojik getirilerine karşı uyumu da etkileyecektir. Dolayısıyla işletme nazarında kültür; gerçekleştirilen faaliyet tarzına ve yapılanların sonucuna etki eden, belli insanlarca bir araya gelerek oluşturulan, inanışlar, algılar, ananeler ve diğer kişiler oluşan ilişkilerden meydana gelmektedir (Köse vd., 2001: 222; Erdoğan, 1994: 111).

Örgüt kültürü; literatürde kullanılan diğer ismiyle kurum kültürü, aynı kurumda çalışanların tutum, inanç, varsayım ve beklentileri ile bireylerin davranışlarını ve bireyler arası ilişkilerini belirleyen faaliyetlerin nasıl yürütüldüğünü gösteren normlar denetimidir (Erengül, 1997: 25). 
Örgüt kültürünün dış etkenlerle veya bizzat örgütün kendisi tarafından oluşturulduğuna dair farklı görüşler bulunmakla beraber her iki boyutun da örgüt kültürünün oluşumuna katkısının olduğu bir gerçektir. Yeni kurulan bir örgüt, bünyesinde topladığ 1 içsel unsurlarla, etkisinde kaldığı bütün dışsal unsurların katkısıyla kendine has bir kültür oluşturmaya başlar (Genç, 1993: 301).

Örgüt içinde bireyler arası etkileşim modelleri, kullanılan dil, imge ve temalar gözlemlendikçe örgüt kültürünün özellikleri ortaya çıkacaktır. Toplumların tarihleri, kültürlerinin oluşumunda etkili olduğu gibi şirketlerin tarihleri ve geçirdikleri krizler örgüt kültürünün oluşmasında etkilidir. Ortak değerler, inançlar, ortak anlam ve anlayış örgüt kültürünün içeriğini oluştururlar (Gök, 2007: 42).

Örgüt kültürü öğrenilmiş veya daha sonra kazanılmış bir olgudur. Yazılı metin olarak görülmemektedir. Örgüte dâhil olan üyelerin düşünce yapılarında, idrak ve hafizalarındaki inanç ve beklentiler olarak yer almaktadır ve gruba sonradan dahil olanlar arasında paylaşabilecekleri niteliktedir (Eren, 2000: 122-123 ).

Örgüt kültürünü daha iyi anlayabilmek, uygulamada nasıl ele alındığını ve ölçümlendiğini kavrayabilmek amacıyla ortaya koyulan modellemeleri incelemek faydalı olacaktır.

\subsection{1. Örgüt Kültürü Boyutları}

Araştırmacılar çevre şartlarının örgüt üzerinde etkisini ya da örgütün sahip olduğu yapısını oluşturan hiyerarşi, haberleşme, kontrol ve yetki gibi sistemlerin kullanılma tarzına ve şiddetine göre pek çok örgütün farklı kültürleri bünyesinde barındırdıklarını keşfetmişler ve bu keşifleri sonucunda ortaya koydukları kriterlere göre kendilerine ait modelleri oluşturmuşlardır. Yapılan çalışmalar incelendiğinde Parsons'ın “AGIL” Modeli, Ouchi'nin Z Modeli, Peters ve Waterman'ın Modeli, Hofstede'in Modeli, Cameron ve Quinn'in Rekabetçi Değerler Yaklaşımı, Deal ve Kennedy'nin Modeli, Kilmann'ın Modeli ve Handy'nin örgüt kültürü modelleri karşımıza çıkmaktadır. Araştırma kapsamında Cameron ve Quinn'in "Rekabetçi Değerler Yaklaşımı" üzerinde durulmuştur.

Cameron ve Quinn'in (1999: 1) modelinin temelinde, örgütün etkinliği için kişilere ait olan normları ve örgütlerin neyi etkili yaptıkları soruları üzerine yapılan ampirik sonuçlar bulunmaktadır. Yazarlara göre kültür, normlar, varsayımlar ve yorumlamayla ifade edilebilmektedir. Unsurların ortak değerler altında toplanabileceğini belirten yazarlar, kültür tiplerinin de bu ayrımdan faydalanarak sınıflandırılabileceğini belirterek bir model geliştirilebileceğini ifade etmişlerdir. Araştırmacılar geliştirdikleri bu model ile işletmenin finans bakımından başarısının yanı sıra örgüte dahil olan üyelerin beklentileri ve onları motive eden ücret, uygun çalışan yönetimi gibi uygulamaların da etkin yönetime dahil olduğunu belirtmektedir. İşletmelerin daha başarılı veya etkin stratejilerinin bulunması ve bunların uygulanması noktasında ise işi yapan çalışanların istek ve arzularına, bünyelerinde bulunan değişim ve yenilik yapma kapasitesiyle doğru orantılı olduğu sonucuna varmışlardır (Eren, 2000:131). Araştırmacılar, örgütün denetim yönelimli tepkileri ile iç ve dış odaklı işleyiş biçimlerinin etkileşimi sonucunda aşağıda açıklanan birbirinden farklı dört örgütsel kültürün oluştuğunu ileri sürmektedir (Çelik, 2000: 24).

Rekabetçi değerler modeli Klan, Adokrasi, Hiyerarşi ve Piyasa Kültürü olmak üzere 4 ayrı kültür tipinde tanımlanmaktadır. Bu kültür tipleri ise her biri kendi içinde baskın örgütsel 
nitelikler, liderlik stilleri, kaynaştırma mekanizmaları ve stratejik önem gibi faktörler etrafında toplanmışlardır.

Kültür tarzlarının tanımlandığı şekil iki ana eksenden meydana gelmektedir. Bu şekli oluşturan eksenlerden dikey olanı organik süreçlerin mekanik süreçlere yönelik yayılımına yer vermektedir. Organik süreçler işletmenin sahip olduğu esnekliğe, kendi bünyesinde oluşmasına değer verirken, mekanik süreç ise denetime, denge ve düzene esneklikten daha fazla önem göstermektedir. Organik ve mekanik süreçler birbirleriyle zit özellikleri bünyelerinde barındırmaktadır. Yatay eksen ise dış konumlandırma ve dâhili koruma boyutlarını içermektedir. Dâhili koruma düzenleme ve bütünleşme çabalarını açıklarken daha çok pazar özelliklerine ve yeniliğe odaklanmakta ve bu iki boyutta birbirleriyle zıt özellik göstermektedirler (Eren, 2000: 132).

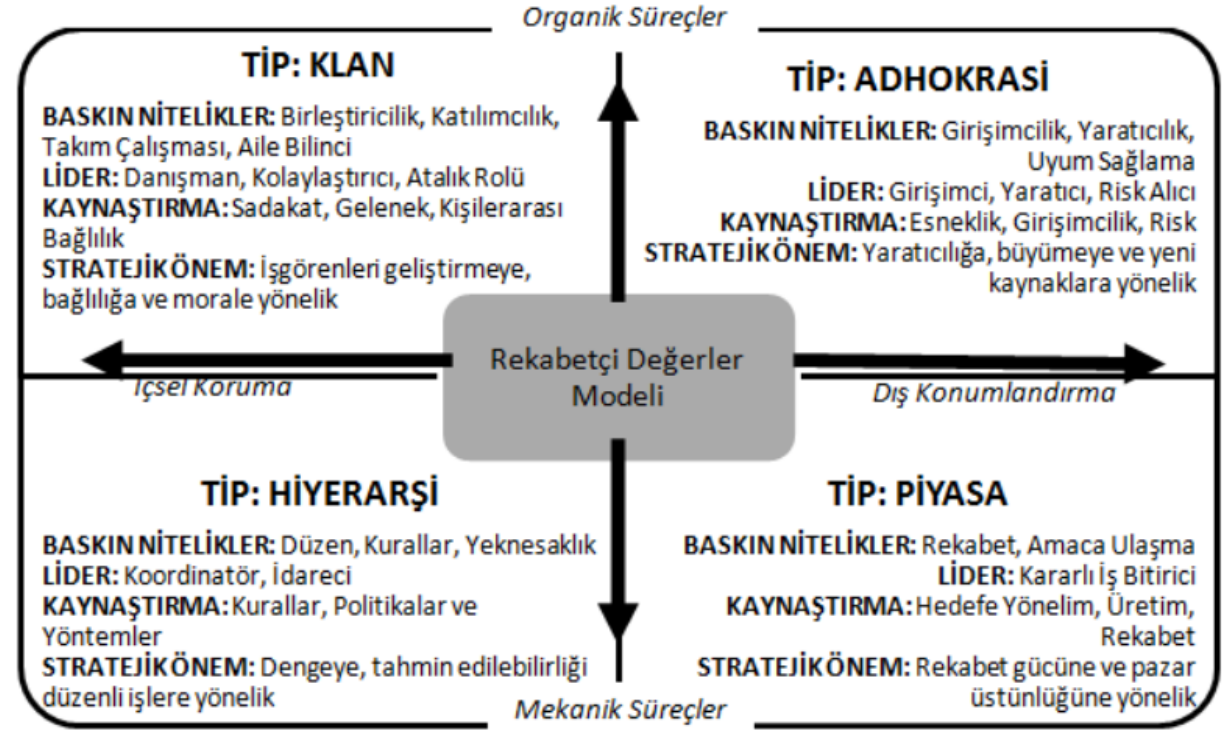

Şekil 1. Rekabetçi Değerler Modeli ve Örgüt Tipolojisi

Kaynak: Deshpande vd., 1993; Eren, 2000.

Klan Kültürü: Klan kültür boyutu, içe bakan, yakınlığın ve dayanışmanın önemli olduğu, örgüt içindeki bağlılığın ön planda olduğu, resmi olmayan denetim safhaları baskın olan örgüt türlerini tanımlamaktadır. Bu tür işletmeler birer aile gibidirler (Erdem, 2007: 66).

Klan kültür boyutunda örgüt yöneticisi akıl veren merci ve hatta aileden biri gibi düşünülür. Örgüt bünyesinde çalışanlar birbirleri arasında sadakate ve gelenekçi olmaya özen gösterirler. Elde edilebilecek başarının kıstası olarak da müşterilerin duyarlılığı, müşteri veya müşteri adaylarının ilgisi olarak kabul edilebilir (İşcan ve Timuroğlu, 2007: 123).

Hiyerarşi Kültürü: Hiyerarşi kültür boyutu endüstri camiasında uzun yıllar yaşamını devam ettirmiş örgütlerde görülebilen kültür boyutu olarak karşımıza çıkmaktadır. Bu örgüt kültürünün odak noktası içsel organizasyon ve temel vurgusu ise istikrardır. İşletme mevcut düzenin ve uygulamaların istikrarlı bir şekilde yürütülmesi amacıyla çalışanlarını güvenlik, emirler, kurallar ve düzenlemeler ile motive etmeye çalışmaktadır. Bu kültürdeki liderler 
tutucu ve tedbirli olmayı tercih eder, teknik meselelere özel bir ilgi gösterirler. Kültürün işletme içindeki tesiri kontrol mekanizmaları, istikrarın sürdürülmesi ve etkinlik faaliyetleri ile sürdürülemeye çalışılmaktadır (Denison ve Spreitzer, 1991: 6). Ayrıca iş süreçlerinde aksama yaşamamak için ölçümleme, dokümantasyon ve bilgi yönetimine özel ilgi gösterilir (DiPadova ve Faerman, 1993).Belli resmi kalıplar içinde bulunmayı sağlar. Örgütte mevcut düzeni sürdürmek çok önemlidir. Uzun vadede verimlilik ve durağanlıkla ilgilenilir (Özenli, 2006: 22).

Adokrasi Kültürü: Adokrasi kültür boyutu, enformasyonun fazla yüklenmesi ya da belirsizlik karşısında esneklik, uyum ve yeniliği özendirmektedir. Örgütsel bütünlük ve danışmanlık düşük seviyede olup kişisel gelişim ve inovasyon özendirilmekle birlikte bu çalışanlardan beklenmektedir. Dinamikliğin yüksek olduğu bu boyutta kişilerin elde ettiği kazanımları, inovasyonu ve riski kabul etmeleri beklenmektedir. Adokrasi boyutunda işletmelerde kısa dönemden ziyade uzun dönemde yeni kaynakları bulma ve büyüme üzerinde yoğunlaşma görülmektedir. Bu boyutta başarı tek ve yeni ürün ya da hizmet olduğu zaman kabul edilen bir olgudur. İşletmenin ürettiği ürün ya da hizmette aldığı liderlik önemli sayılmaktadır. Danışmanlık şirketlerinde ve yazılım şirketlerinde adokrasi kültürü gözlemlenebilmektedir (İşcan ve Timuroğlu, 2007: 123).

Adokrasi kültür boyutunun geçerli olduğu işletmelerde girişimci, dinamik ve kendini geliştiren bir iş ortamı bulunmaktadır. Bireyler iş yaparken samimiyetle birlikte risk almayı da seven bir yapıda bulunmaktadırlar. Yöneticiler risk alan ve yenilikçi çalışanları özendirirler, onları ön plana çıkarırlar ve gereken önemi verirler. İşletme kişisel özgürlüğü ve girişimi özendirmektedir. Bu kültür boyutunun gelişmesinde yöneticinin sergilediği davranış şekli, yeniliğe açık olması, girişimci bir kişiliği olması ve risk almaktan kaçınmayan bir yapıya sahip olması önemli bir etken olmaktadır (Kayalar ve Özmutaf, 2007: 166).

Piyasa Kültürü: Piyasa kültürü, dışa odaklanmayı, rekabet ortamını ve verimliliği önemseyen ancak denetim yönünü ve durağanlığı da bünyesinde bulunduran örgüt ortamlarını ifade ederken kullanılmaktadır (Erdem, 2007: 66).

$\mathrm{Bu}$ kültürde lider işletme performansı ve sonuçlarına odaklanır, kaynak dağılımında öncelikleri belirler ve işin bir an önce bitirilmesine önem verir (Hart ve Quinn, 1993). Ayrıca piyasa odaklı bir anlayışla stratejik analizlere ve stratejik liderlik özelliklerine değer verir (Panayotopoulou vd., 2003). Ürün yönelimli örgütlerde görülür. Kazanma arzusu ön plandadır ve uzun vadede yarışmacı etkinliklerle ölçülebilir hedeflere önem verilir. Başarı pazar payının artışı ile ölçülür (Özenli, 2006: 22).

\section{2. Örgütsel Adalet}

Adalet, bireylerin yaşadığı her dönemde ve uygarlıkta, hali hazırdaki toplumsal yaşantının vazgeçilmez bir unsuru olmuştur (Taşkıran, 2011: 3). Buna ek olarak, küreselleşen dünyada artan rekabet koşulları ve bilginin kazandığı yeni anlamlar, işletme çalışanlarının adalet algılarını daha fazla ön plana çıkartmıştır (Atalay, 2010: 41).

Üzerinde oldukça kapsamlı araştırmalar yapılarak yönetim literatürüne kazandırılan örgütsel adalet kavramı, çok farklı bilim dallarının kollektif çalışmaları sonucunda, farklı şekillerde tanımlanmıştır (Taşkıran, 2011: 93). Örgütsel adalet kavramı en sade anlatımıyla çalışanların işletmedeki adalet algılarının bütünüdür ve bu sebeple işletmenin bir azasının algısına göre son derece adaletli olan bir uygulama, bir başkasına karşı adaletli gelmeyebilmektedir 
(Atalay, 2010: 42). Taşkıran (2011) konunun, "personellerin birimlerinde veya çalıştığ1 firmalarında kendilerine adaletli davranılıp davranılmadığına nasıl karar verdikleri ve bu kararların işle ilgili diğer etkenleri hangi yönde ve nasıl etkilediğiyle ilgili” olduğunu belirtirken Dinçer (2008) "İş görenlerin iş tutumlarını etkileyen, bireyin örgüt içerisinde iş bölümü, ücret ve dinlenme koşullarını da kapsayan uygulamalarla birlikte, örgüt içerisindeki sosyal etkileşim kalitesini belirleyen bir yapı" olarak kavramı tanımlamaktadır.

Bir kazanım adil olabilir, ancak ona ulaşmak için izlenen işlemler adil olmayabilir. Bunun için, yöneticiler sadece kararlarında değil aynı zamanda bu kararlara nasıl ulaştıkları konusunda da adil olmalıdırlar (Lambert, 2003: 157'den Akt. Eker, 2006: 18). Personellerin çalıştıkları ortam veya çalıştıkları şartlar yöneticilerin onlara adaletli veya adaletsiz davranıp davranmadığını gösteren bir yoldur. Bireyler, kendi bulundukları ortamda adil bir şekilde davranış sergilenmediğini hissettiklerinde, faaliyet gösterdikleri işletmeye negatif davranışlar geliştirip, demoralize olup, çalıştıkları örgüte yönelik negatif algı ve tutumlar geliştirebilmektedir (Yıldırım, 2007: 256).

\subsection{1. Örgütsel Adalet Boyutları}

Örgütsel adalet kavramının algılanması yönündeki karmaşıklık birçok soruyu karşımıza çıkarmaktadır. Örneğin; örgüt içinde kararların nasıl alındığı, yöneticilerin çalışanları ne tür bir muameleye tabi tuttuğu veya nasıl bir ücret politikası izlediğine kadar bütün sorular örgütsel adalet kavramının içeriğindedir (Özkalp ve Kırel, 2013: 655). İlk araştırmalara bakıldığında Tyler ve Folger (1980) kavramı dağıtımsal ve prosedürel adalet olmak üzere iki boyutta incelenmiştir. Niehoff ve Moorman (1993) ise bu iki boyuta ilave olarak etkileşim adaleti boyutunu eklemiştir. Bu çalışmada Niehoff ve Moorman'ın ortaya koyduğu 3 boyutlu örgütsel adalet modeli kullanılmaktadır.

Dağıtımsal Adalet: İşletmeler mal veya hizmet üreterek kar elde edebilmek amaciyla girişimci tarafindan maddi olan ve olmayan unsurlarla işgücünün bir araya getirilmesi neticesinde faaliyet göstermektedir. Örgütsel hedeflere ulaşabilmesi açısından eldeki maddi olan ve olmayan unsurların tahsisinde ve hedeflere ulaşılması halinde de elde edilen kazanımların tüm paydaşlara paylaştırılmasında belirli yöntemlere başvurulmaktadır. Eldeki kıt kaynakların tahsisine ve kazanımların dağıtılmasına esas teşkil eden bu uygulamaların çalışanlar tarafından adil bir şekilde algılanma seviyesi ise dağıtımsal adalet algısını meydana getirmektedir (Yanık, 2014: 76). İşcan ve Naktiyok'a (2004) göre dağıtımsal adalet, karşılaşılan sonuçların ya da ödüllerin hakkaniyeti ile ilgili adalet algısıdır. Bu kurallara göre örgütsel kaynakların dağıtımı sonrasında hak ettiğini aldığını düşünen çalışanlar, daha olumlu davranışlar ve performanslar sergileyecektir.

Prosedürel Adalet: Prosedür adaleti, örgütsel kaynakların dağıtımını belirleyen prosedürlere yönelik algılanan adalet olarak tanımlanmaktadır. Başka bir deyişle prosedür adaleti, kazanımları belirlemede kullanılan yöntemler, araçlar ve süreçlere yönelik algılanan adalettir. Buna göre prosedür adaleti kavramı ile çalışanların örgütsel kararlarının adaletini tayin ederken, sadece bu kararların ne olduğu ile ilgilenmedikleri aynı zamanda bu kararları belirleyen prosedürlerle de ilgilendikleri savunulmaktadır. Prosedür adaleti, örgütlerde dağıtım adaletinin açıklayamadığı durumları ifade edebilmektedir (Çakmak, 2005: 31).

Ücret ile ilgili bir karara varırken amirin ya da örgütün takip ettiği politika ve prosedürlerin ne derece adil olduğu, bu politika ya da prosedürlere iş görenlerin ne derece güven duyduğu prosedürel adalet kavramının konularıdır (Doğan, 2002: 72). 
Etkileşimsel Adalet: Etkileşimsel adalet boyutu, prosedürel adaletin daha kapsamlı şekilde ele alınmasıyla karşımıza çıkmakla birlikte örgütsel faaliyetlerin kişilere bakan tarafıyla ilgilenmektedir. Örgütsel adaletin üçüncü boyutu olan etkileşimsel adalet boyutu, adaletin ortaya çıktığı kaynakla ve adalete maruz kalanların aralarındaki iletişim aşamasının saygı, doğruculuk ve nezaket çerçevesi altında değerlendirilip uygulanması esas amaç olarak algılanmaktadır (Işık vd., 2012: 255). Çalışanlar, yöneticiler tarafından alınıp uygulanan işlemlerin ne olduğunu ve bu işlemlerin uygulanması aşamasında kendilerine yöneticiler tarafından nasıl davranış sergilendiğine ve bu kararların yeterli düzeyde açıklanıp açıklanmadığına dikkat etmektedir. İşlemlerin uygulamaya konulma aşamasında çalışanların maruz kaldıkları bireyler arasındaki davranışların kalitelerine yönelik algıları, etkileşim adaletini oluşturmaktadır (Yılmaz, 2004: 27).

\subsection{Bilgi Paylaşımı}

Bilgi, insanın etrafında olup bitenleri tam ve doğru olarak kavramasını sağlayan kişiselleştirilmiş enformasyondur. Bilgi, kendini düşünceler, öngörüler, sezgiler, fikirler, alınan dersler, uygulamalar ve yaşanan deneyimler şeklinde gösterir (Barutçugil, 2002: 10).

Bilgi paylaşımı, bir bireyin sahip olduğu bilgiyi diğerlerinin anlaması, benimsemesi ve kullanması için onlarla paylaşmasını içeren bir süreçtir (Ipe, 2003, 341). Bilgi paylaşımı; bilginin diğerleri ile değişimini ve yardımlaşmayı gerektiren bir dizi davranıştır. Bu dizi davranış enformasyon paylaşımından farklılık göstermektedir. Organizasyonun diğer aşamalarındaki tipik enformasyon aktarımlarından farklıdır. Bilgi paylaşımı karşılıklılık durumu içerir, enformasyon paylaşımı ise tek yönlüdür ve talep edilmeden verilme durumu vardir (Connelly ve Kelloway, 2003: 294).

Bilgi paylaşımında, temel olarak bilginin belli bir kaynaktan çıkarak belli bir hedefe ulaşması oldukça önemlidir. Bilgi paylaşımı bu yönüyle bilgi transferinden ayrılmaktadır. Çünkü bilgi transferinde bilginin dağıtımı söz konusudur ve hedefine ulaşıp ulaşmadığı test edilmez. Ayrıca bilgi paylaşımında bilgiyi kabul edecek olan tarafın gönüllü olması gerekir. Yani bilgi paylaşımı taraflar arasında bir zorlama olamadan bireylerin kendi aralarında uzlaşmayla bilginin değişimi söz konusudur (Demirel ve Yeniçeri, 2007: 222). Dolayısıyla araştırma kapsamında bilgi paylaşımı; bilgi paylaşımına yönelik niyet ve tutum olarak iki bağımlı değişken şeklinde ele alınmıştır.

\section{METODOLOJI}

Araştırmanın amacı, hedef kitlesi, verilerin toplanması ve değerlendirilmesinde daha objektif olunması gibi kriterlerle birlikte deneklerin kişisel özelliklerinin, örgütsel kültür ve adalet algısının, bilgi paylaşımı niyetinin ve tutumunun belirlenecek olması da nicel yöntemin tercih edilmesinde etkili olmuştur. Verilerin toplanmasında sahip oldukları özellikleri bakımından anket tekniği kullanılmıştır. Metodoloji kapsamındaki diğer konulara aşağıda detaylı şekilde yer verilmiştir.

\subsection{Evren ve Örneklem}

Araştırmanın evrenini bilgi üretme merkezi ve bilginin temel değer olduğu bir ortam olarak düşünülen Düzce Üniversitesi'nde çalışmakta olan akademik ve idari personeller oluşturmaktadır. Üniversitenin bilim üreten bir merkez oluşu ve bunu da paylaşarak gerçekleştirmesi temel tercih edilme nedenidir. Araştırma yapılırken evrenin tamamına ulaşılmaya çalışılmıştır. Bu doğrultuda Düzce Üniversitesi Personel Daire Başkanlığı'ndan 
elde edilen personel sayısı dikkate alınmıştır. Verilen bilgilere göre Düzce Üniversitesi'nde çalışmakta olan 976 akademik personel ve 789 idari personel olduğu saptanmıştır. Bu bilgiler doğrultusunda 1765 personelin tamamına ulaşılmaya çalışılmıştır. Tüm personellere ulaşmak için en az birer kez odalarına gidilmiş olup yaklaşık olarak 600 kişiyle konuşulmuş ve bunların 338 tanesi ankete katılmış ve 16 anket cevaplayıcıların anketi doldurmasından kaynaklanan sebeplerden dolayı değerlendirmeye alınmamış ve 322 personelin anketleri değerlendirilmeye alınabilmiştir.

Evrenin tamamına ulaşılmaya çalışılmış ancak bu amaca ulaşılamamıştır. Bu nedenle örneklem yoluna gidilmiştir. Öncelikle evreni temsil edecek örneklem sayısını tespit etmek amacıyla " $n=$ N.t2.p.q / d2.(N-1)+t2.p.q" (Karagöz, 2014) formülü uygulanmıştır. Alınan değerler formüldeki yerlerine koyulduğunda örneklem sayısı (n) 316 çıkmaktadır. Ulaşılan 322 anketin ortaya çıkan örneklem sayısını temsil edebilecek nitelikte olduğu görülmektedir. Örnekleme yöntemi olarak tabakalı örnekleme yöntemi (akademik ve idari personel olarak) seçilmiş ve araştırmaya katılmak isteyen personellere anket çalışması uygulanmıştır.

\subsection{Kullanılan Ölçekler}

Araştırma sürecinde kullanılan dört temel değişkeni ve yedi alt boyutu ölçmek üzere kullanılan ölçeklerle ilgili bilgiler aşağıda paylaşılmaktadır.

\subsection{1. Örgüt Kültürü}

Deshpande ve diğerlerinin (1993) kullandığı ölçeğin temelleri Cameron ve Freeman'ın (1991) çalışmasına dayanmaktadır. Deshpande ve diğerleri (1993) tarafından geliştirilmiş 16 ifadeli ölçekte örgüt kültürü ile ilgili ifadeler dört boyutta ele alınmıştır. Ölçek Erdem (2007) tarafından Türkçeye çevrilmiş ve 256 hastane çalışanı üzerinde uygulanmıştır. Dört boyuttaki her bir ifade dört örgüt kültürü tipi (klan, hiyerarşi, adokrasi ve piyasa) ile ilişkilidir. Boyutların orijinal güvenilirlik katsayıları 0.82 ila 0.42 arasında değişmektedir. Araştırma kapsamında yapılan güvenilirlik analizlerine göre ise katsayılar 0.85 ila 0.68 arasında değişmektedir ki bu ölçeklerin güvenilir olduğunu ortaya koymaktadır.

\subsection{2. Örgütsel Adalet}

Örgüt içindeki adalet algısını ölçmek üzere, Niehoff ve Moorman (1993) tarafından geliştirilen ve Yıldırım (2002; 2007) tarafından Türkçe’ye çevrilip güvenilirlik ve geçerliliği ortaya konan ölçekten yararlanılmıştır. Farklı iş sonuçlarının adilliğini tayin eden adil dağıtım ölçeği 5, işyerinde karar alma mekanizmalarını ölçen adil prosedür ölçeği 6 , çalışanların kendi ihtiyaçlarının dikkate alındığını ne kadar hissettiklerini ve iş kararları için yeterli açıklamanın ne kadar yapıldığını ölçen adil etkileşim ölçeği ise 9 maddeden oluşmaktadır (Yıldırım, 2007:264). Alt boyutların güvenilirlik katsayıları orjinalinde 0.92 ila 0.74 ve Türkçe'ye çevrilen halinde 0.95 ila 0.81 arasındadır. Araştırma kapsamında yapılan güvenilirlik analizlerine göre ise katsayılar 0.96 ila 0.91 arasında değişmektedir ki bu ölçeklerin oldukça güvenilir olduğunu ortaya koymaktadır.

\subsubsection{Bilgi Paylaşma Niyeti}

Bock ve arkadaşları (2005) tarafından geliştirilmiş olan bilgi paylaşma niyeti ölçeği örtük ve açık bilgi paylaşma niyeti olmak üzere iki boyuttan oluşmaktadır. Yapılan araştırma kapsamında ölçeğin 3 maddeden oluşan örtük bilgi paylaşma niyeti boyutu kullanılmıştır. Ölçeğin Türkçeye uyarlanması Aydıntan ve arkadaşları (2010) tarafından gerçekleştirilmiştir. 
Orijinal ölçeğin güvenilirlik katsayısı 0.92 gerçekleştirilen araştırmada ise 0.92 olarak belirlenmiştir ki bu ölçeğin oldukça güvenilir olduğunu göstermektedir.

\subsubsection{Bilgi Paylaşma Tutumu}

Bilgi paylaşma tutumunu belirlemeye yönelik kullanılan ölçek Van den Hoof ve De Ridder (2004) tarafindan geliştirilmiştir. Ölçek bilgi paylaşma ve bilgi toplama olarak iki boyuttan oluşmaktadır. Yapılan araştırmada bilgi paylaşma tutumuna yönelik olan kısmı kullanılmıştır. Ölçeğin Türkçe'ye uyarlanması Ayazlar (2012) tarafından gerçekleştirilmiştir. Orijinal ölçeğin güvenilirlik katsayısı 0.85 Türkçe'ye çevrilmiş halinde 0.96 ve gerçekleştirilen araştırmada ise 0.93 olarak belirlenmiştir ki bu ölçeğin oldukça güvenilir olduğunu göstermektedir.

\subsection{Araştırma Modeli ve Hipotezler}

Literatür araştırması dikkate alınarak oluşturulan araştırma modeli; öncelikle örgüt kültürü, örgütsel adalet, bilgi paylaşım niyeti ve bilgi paylaşma tutumu olmak üzere dört temel değişken ve yedi alt boyut olarak kurgulanmıştır.

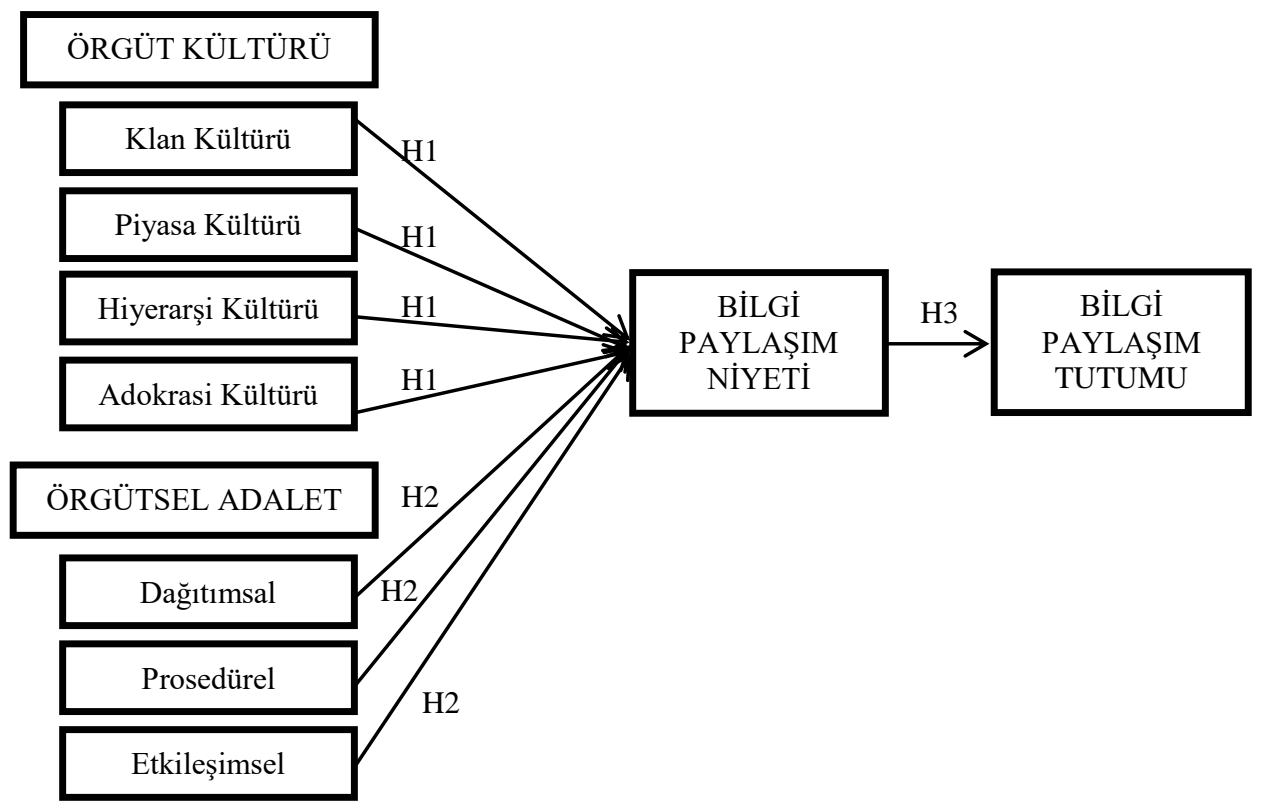

Şekil 2. Araştırma Modeli

Araştırma modelinde ortaya konulan hipotezler şu şekildedir;

H1a: Örgüt kültürü tiplerinden klan kültürü örgütsel bilgi paylaşım niyetini etkilemektedir.

H1b: Örgüt kültürü tiplerinden piyasa kültürü örgütsel bilgi paylaşım niyetini etkilemektedir.

H1c: Örgüt kültürü tiplerinden hiyerarşi kültürü örgütsel bilgi paylaşım niyetini etkilemektedir. 
H1d: Örgüt kültürü tiplerinden adokrasi kültürü örgütsel bilgi paylaşım niyetini etkilemektedir.

H2a: Örgütsel adalet boyutlarından dağıtımsal adalet örgütsel bilgi paylaşım niyetini etkilemektedir.

H2b: Örgütsel adalet boyutlarından prosedürel adalet örgütsel bilgi paylaşım niyetini etkilemektedir.

H2c: Örgütsel adalet boyutlarından etkileşimsel adalet örgütsel bilgi paylaşım niyetini etkilemektedir.

H3: Örgütsel bilgi paylaşım niyeti örgütsel bilgi paylaşım tutumunu etkilemektedir.

\subsection{Katılımcılara İlişkin Veriler}

Araştırmaya katılanların \%60’ı erkek ve \%65'i evlidir. Yaş aralığının 26-35 düzeyinde yoğunlaştığı (\%59), eğitim düzeyinin ise lisans (\%34) ve yüksek lisans (\%24) ve doktora (\%29) seviyesinde yoğunlaştığ1 tespit edilmiştir. Akademik bir kurum olan üniversitede böyle bir eğitim düzeyi dağılımının ana nedeni katılımcıların hem akademik (\%48) hem de idari (\%52) personellerden oluşmasıdır. Araştırmaya katılanların bir kısmı (\%32) hali hazırda idari görevlerine devam etmektedir. Unvan konusundaki dağılımlara bakıldığında birçok katılımcının bu soruyu boş bıraktığı görülmüştür. Cevaplayanlara göre idari personelden en çok katılımın memurlardan (\%33), akademik personelden ise Öğretim Görevlileri (\%15) ve Dr. Öğretim Üyelerinden (\%13) sağlandığı tespit edilmiştir.

\subsection{Araştırmanın Sınırlılıkları}

Akademisyenler ve idari personeller üzerine yapılan bu araştırmanın en önemli sınırı araştırma evreninde yer alan akademik ve idari personelin bir kısmının veri paylaşımını kabul etmemesidir. Çalışanların bu davranışı sergilemesi de yapmış olduğumuz çalışmanın önemini bir kez daha göz önüne sunmaktadır. Araştırma, sadece Düzce Üniversitesinde görev yapan akademik ve idari personelleri kapsamaktadır. Araştırma kavramsal olarak da ulaşılabilen yazın ile sınırlanmıştır.

\section{BULGULAR}

\subsection{Betimsel Analizler}

Betimleyici istatistikler kapsamında her bir değişkene ilişkin ortalama, standart sapma, güvenilirlik katsayıları ve soru sayılarına ilişkin bilgiler paylaşılacaktır.

Tablo 1. Değișkenlere İlișkin Tanımlayıcı İstatistikler

\begin{tabular}{|c|c|c|c|c|}
\hline Yapılar & $\overline{\boldsymbol{x}}$ & Standart Sapma & Soru Sayısı & Güvenilirlik Katsayısı \\
\hline Klan Kültürü & 2,98 & 0,95 & 4 &, 83 \\
\hline Adokrasi Kültür & 3,12 & 0,91 & 4 &, 85 \\
\hline Hiyerarşi Kültürü & 3,40 & 0,76 & 4 &, 68 \\
\hline Piyasa Kültürü & 3,26 & 0,74 & 4 &, 69 \\
\hline Prosedürel Adalet & 2,92 & 1.00 & 6 &, 92 \\
\hline Dağıtımsal Adalet & 3,16 & 1,01 & 5 &, 91 \\
\hline Etkileşimsel Adalet & 3,31 & 1,00 & 9 &, 96 \\
\hline Bilgi Paylaşma Niyeti & 4,06 & 0,81 & 3 &, 92 \\
\hline Bilgi Paylaşma Tutumu & 3,98 & 0,75 & 6 &, 93 \\
\hline
\end{tabular}


Değişkenlere yönelik tanımlayıcı istatistikler incelendiğinde çalışanların örgüt içinde baskın olarak hissettikleri kültür tipinin hiyerarşi kültür yapısı ( : 3.40) olduğu görülmektedir ki kamusal alanda faaliyet gösteren bir yapı olan üniversitelerden adokrasi kültürünün de yüksek düzeyde olması beklentisi tam anlamıyla karşılanamamıştır. İşletme içinde algılanan adalet türleri değerlendirildiğinde ise etkileşimsel adalet boyutunun $(: 3.31)$ daha baskın bir şekilde hissedildiği görülmektedir. Değişkenlere ve alt boyutlarına yönelik güvenilirlik katsayıları değerlendirildiğinde ise Kayış'ın (2010) belirttiği $\alpha$ değerlerine göre değişkenlere yönelik güvenilirlik katsayılarının kabul edilebilir düzeyde olduğunu söyleyebiliriz.

\subsection{Hipotezlere Yönelik Bulgular}

Araştırmanın bu bölümünde örgüt kültürü tiplerinin ve örgütsel adalet boyutlarının örgütsel bilgi paylaşım niyeti üzerindeki etkileri ve örgütsel bilgi paylaşım niyetinin örgütsel bilgi paylaşım tutumuna yönelik etkileri regresyon analizi yardımıyla incelenecektir.

Tablo 2. Örgüt Kültürü Tipleri ve Örgütsel Bilgi Paylaşım Niyeti Arasındaki Regresyon Analizi Bulguları

\begin{tabular}{|c|c|c|c|c|c|c|c|c|c|}
\hline Değişkenler & $\mathbf{B}$ & $\begin{array}{c}\text { Standart } \\
\text { Hata }\end{array}$ & $\boldsymbol{\beta}$ & $\mathbf{t}$ & $\mathbf{p}$ & İkili r & $\begin{array}{c}\text { Kısmi } \\
\mathbf{r}\end{array}$ & Tol. & VIF \\
\hline (Sabit) & 3,037 &, 215 & - & 14,103 &, 000 & - & - & - & - \\
\hline Hiyerarşi &, 294 &, 086 &, 276 & 3,400 &, 001 &, 285 &, 188 &, 441 & 2,27 \\
\hline Klan &,- 061 &, 080 &,- 072 &,- 771 &, 441 &, 167 &,- 043 &, 329 & 3,04 \\
\hline Adokrasi &, 084 &, 088 &, 095 &, 949 &, 343 &, 211 &, 053 &, 289 & 3,46 \\
\hline Piyasa &,- 015 &, 091 &,- 014 &,- 167 &, 869 &, 196 &,- 009 &, 420 & 2,38 \\
\hline $\mathrm{R}=0,289, \mathrm{R}^{2}=0,084, \mathrm{~F}=7,243, \mathrm{p}=0,000$, Durbin-Watson=2,060 \\
\hline
\end{tabular}

Yordayıcı değişken ile bağımlı değişken arasındaki ikili ve kısmi korelasyonlar incelendiğinde, örgüt kültürü tiplerinden hiyerarşi kültürü ile bilgi paylaşım niyeti arasında pozitif ve düşük düzeyde bir ilişkinin $(r=, 29)$ olduğu, ancak diğer değişkenler kontrol edildiğinde iki değişken arasındaki korelasyonun $\mathrm{r}=, 19$ olarak hesaplandığı görülmektedir. Diğer örgüt kültürü tipi olan adokrasi kültürü ile bilgi paylaşma niyeti arasında pozitif ve düşük düzeyde $(r=, 21)$ bir ilişki varken, diğer değişken kontrol edildiğinde bu korelasyonun $\mathrm{r}=, 05$ olarak hesaplandığı görülmektedir. Diğer örgüt kültürü tipleri olan klan ve piyasa boyutları ile bilgi paylaşma niyeti arasında pozitif ve düşük düzeyde $(r=, 17-r=, 20)$ bir ilişki varken, diğer değişken kontrol edildiğinde bu korelasyonların $r=-, 043$ - r=-,009 olarak

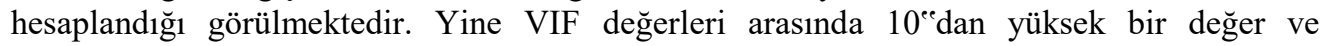
tolerance değerleri arasında 0.20 'den daha düşük bir değer olmadığı için bağımsız değişkenler arasında çoklu bağlantılılığın olmadığı söylenebilir. Ayrıca Durbin-Watson katsayısı $(2,060)$ bağımsız değişkenler ile hata terimleri arasında sorunlu bir ilişkinin olmadığını göstermektedir.

Tablodaki bulgulara göre bağımsız değişkenlerin bağımlı değişkeni açıklama düzeyi istatistiki açıdan anlamlıdır $\left(\mathrm{R}^{2}=, 084, \mathrm{~F}=7,243, \mathrm{p}=, 000\right)$. Standardize edilmiş regresyon katsayılarına ( $\beta$ ) göre, örgüt kültürü tiplerinin bilgi paylaşım niyeti üzerindeki göreceli önem sırası; hiyerarşi, adokrasi, klan ve piyasa şeklindedir. Regresyon katsayılarının anlamlılığına ilişkin t-testi sonuçları incelendiğinde ise, hiyerarşi boyutunun bilgi paylaşım niyeti üzerinde pozitif yönde etkisinin olduğu, adokrasi, piyasa ve klan boyutlarının ise anlamlı bir etkiye sahip olmadığ1 görülmektedir. Bu bulgular 1şığında; "H1c: Örgüt kültürü tiplerinden hiyerarşi kültürü bilgi paylaşım niyetini etkilemektedir" hipotezi kabul edilmekte, "H1a: Örgüt kültürü tiplerinden klan kültürü bilgi paylaşım niyetini etkilemektedir", "H1b: Örgüt kültürü 
tiplerinden piyasa kültürü örgütsel bilgi paylaşım niyetini etkilemektedir" ve "H1d: Örgüt kültürü tiplerinden adokrasi kültürü bilgi paylaşım niyetini etkilemektedir" hipotezleri reddedilmektedir.

Tablo 3. Örgütsel Adalet Boyutları ve Örgütsel Bilgi Paylaşım Niyeti Arasındaki Regresyon Analizi Bulguları

\begin{tabular}{|c|c|c|c|c|c|c|c|c|c|}
\hline Değişkenler & $\mathbf{B}$ & Standart Hata $\mathbf{B}$ & $\boldsymbol{\beta}$ & $\mathbf{t}$ & $\mathbf{p}$ & İkili r & Kısmi r & Tol. & VIF \\
\hline (Sabit) & 3,468 &, 164 & - & 21,086 &, 000 & - & - & - & - \\
\hline Prosedürel &, 150 &, 086 &, 185 & 1,745 &, 000 &, 224 &, 097 &, 265 & 3,78 \\
\hline Dağıtımsal &, 073 &, 059 &, 091 & 1,234 &, 218 &, 198 &, 068 &, 544 & 1,84 \\
\hline Etkileşimsel &,- 021 &, 081 &,- 027 &,- 264 &, 792 &, 185 &,- 015 &, 293 & 3,41 \\
\hline $\mathrm{R}=0,234, \mathrm{R}^{2}=0,055, \mathrm{~F}=6,113, \mathrm{p}=0,000$, Durbin-Watson=2,073 \\
\hline
\end{tabular}

Yordayıcı değişken ile bağımlı değişken arasındaki ikili ve kısmi korelasyonlar incelendiğinde, örgütsel adalet boyutlarından prosedürel adalet boyutu ile bilgi paylaşım niyeti arasında pozitif ve düşük düzeyde bir ilişkinin $(r=, 22)$ olduğu, ancak diğer değişkenler kontrol edildiğinde iki değişken arasındaki korelasyonun $\mathrm{r}=, 10$ olarak hesaplandığ1 görülmektedir. Diğer örgütsel adalet boyutu olan dağıtımsal adalet boyutu ile bilgi paylaşma niyeti arasında pozitif ve düşük düzeyde $(\mathrm{r}=, 20)$ bir ilişki varken, diğer değişken kontrol edildiğinde bu korelasyonun $\mathrm{r}=, 07$ olarak hesaplandığ 1 görülmektedir. Diğer örgütsel adalet boyutu olan etkileşim boyutu ile bilgi paylaşma niyeti arasında pozitif ve düşük düzeyde $(\mathrm{r}=, 19)$ bir ilişki varken, diğer değişken kontrol edildiğinde bu korelasyonun $\mathrm{r}=-, 015$ olarak hesaplandığı görülmektedir. Yine VIF değerleri arasında 10'dan yüksek bir değer ve tolerance değerleri arasında 0.20 'den daha düşük bir değer olmadığı için bağımsız değişkenler arasında çoklu bağlantılılığın olmadığı söylenebilir. Ayrıca Durbin-Watson katsayısı $(2,073)$ bağımsız değişkenler ile hata terimleri arasında sorunlu bir ilişkinin olmadığını göstermektedir.

Tablodaki bulgulara göre bağımsız değişkenlerin bağımlı değişkeni açıklama düzeyi istatistiki açıdan anlamlıdır $\left(\mathrm{R}^{2}=, 055, \mathrm{~F}=6,113, \mathrm{p}=, 000\right)$. Standardize edilmiş regresyon katsayılarına ( $\beta$ ) göre, örgütsel adalet boyutlarının bilgi paylaşım niyeti üzerindeki göreceli önem sırası; prosedürel, dağıtımsal ve etkileşimsel şeklindedir. Regresyon katsayılarının anlamlılığına ilişkin t-testi sonuçları incelendiğinde ise, prosedürel boyutunun bilgi paylaşım niyeti üzerinde pozitif yönde etkisinin olduğu, dağıtım ve etkileşim boyutlarının ise anlamlı bir etkiye sahip olmadığı görülmektedir. Bu bulgular 1şığında; "H2b: Örgütsel adalet boyutlarından prosedürel adalet örgütsel bilgi paylaşım niyetini etkilemektedir" hipotezi kabul edilmekte, "H2a: Örgütsel adalet boyutlarından dağıtımsal adalet bilgi paylaşımı niyetini etkilemektedirr" ve "H2c: Örgütsel adalet boyutlarından etkileşimsel adalet bilgi paylaşımı niyetini etkilemektedir" hipotezleri reddedilmektedir.

Tablo 4. Örgütsel Bilgi Paylaşım Niyeti ve Örgütsel Bilgi Paylaşım Tutumu Arasındaki Regresyon Analizi Bulguları

\begin{tabular}{|c|c|c|c|c|c|c|}
\hline Değişkenler & $\mathbf{B}$ & $\begin{array}{c}\text { Standart } \\
\text { Hata }\end{array}$ & $\boldsymbol{\beta}$ & $\mathbf{t}$ & $\mathbf{p}$ & Íkili r \\
\hline $\begin{array}{c}\text { Bilgi Paylaşma } \\
\text { Tutumu }\end{array}$ &, 822 &, 039 &, 764 & 21,176 &, 000 &, 764 \\
\hline $\mathrm{R}=0,764, \mathrm{R}^{2}=0,584, \mathrm{~F}=448,428, \mathrm{p}=0,000$, Durbin-Watson $=1.983$ & \\
\hline
\end{tabular}


Yordayıcı değişken ile bağımlı değişken arasındaki ikili korelasyonlar incelendiğinde, örgüt bilgi paylaşım niyeti ile bilgi paylaşma tutumu arasında pozitif ve yüksek düzeyde bir ilişkinin $(r=, 76)$ olduğu görülmektedir.

Tablodaki bulgulara göre bağımsız değişkenlerin bağımlı değişkeni açıklama düzeyi istatistiki açıdan anlamlıdır $\left(\mathrm{R}^{2}=, 764, \mathrm{~F}=448.428, \mathrm{p}=, 000\right)$. Standardize edilmiş regresyon katsayılarına $(\beta)$ göre, bilgi paylaşım niyetinin bilgi paylaşım tutumu üzerindeki etkisi görülmektedir. Regresyon katsayılarının anlamlılığına ilişkin t-testi sonuçları incelendiğinde ise, bilgi paylaşım niyetinin bilgi paylaşım tutumu üzerinde pozitif yönde önemli bir etkisinin olduğu görülmektedir. Örgüt içinde bilgiyi paylaşma tutumuna ilişkin toplam varyansın \%58'inin bilgi paylaşma niyeti ile açıklandığı ifade edilebilir. Bu bulgular 1şı̆̆ında; "H3: Örgütsel bilgi paylaşım niyeti örgütsel bilgi paylaşım tutumunu etkilemektedir." hipotezi kabul edilmektedir.

\section{SONUÇ ve ÖNERILER}

Kamuya ait kurumlar da özel sektör kuruluşları gibi kendilerini karmaşık ve dinamik şekilde gelişen bir çevrenin içerisinde bulmaktadır. Yapıları içerisinde çalışan personelden daha fazla verim alabilmeleri ve onları verilen görevlerde etkin şekilde istihdam edebilmeleri için kurumsal bir kültür geliştirmeleri gerekmektedir. Bu bağlamda tercih edilen örgüt kültürü yapısına göre örgüt içindeki adalet algısının sağlamlaştırılması ve bunlara bağlı olarak çalışan personeller arasında da bilgi paylaşma niyetinin artması ve bilgi paylaşma niyetini davranışa dönüştürmeleri beklenmektedir.

Yaptığımız çalışma sonucunda örgütsel bilgi paylaşım niyetini dört farklı örgüt kültürü yapısından hiyerarşi kültür yapısının etkilediği tespit edilmiştir. Örgüt içerisindeki bilgi paylaşım niyetinin artmasında otoriter yöneticilerin varlı̆̆ politikaların pozitif yönde etkileyeceği sonucuna varılmıştır. Hiyerarşi kültürüne yönelik literatürde, işletmelerde belli bir otoritenin varlığından, standart kuralların etkinliğinden, işletmede her şeyin yazılı olarak belirlendiğinden ve yüksek düzeyde formalitenin var olduğundan bahsedilmektedir. Örgüt yöneticilerinin yürüttüğü politikalar ve örgüt içi kurallar çalışanları bir arada tutmaya yarayacak, böylelikle çalışanların sürekli birbirleriyle iletişim halinde olmalarının bilgi paylaşma niyetlerini arttıracağı düşünülebilir. Örgütteki işleyişlerin ve tarzların kişilere göre değişmemesi, belli standart yapılar çerçevesinde faaliyetlerin sürdürülmesi çalışanların bilgi paylaşım niyetlerine olumlu etki edeceği söylenebilir.

Özel sektöre yönelik gerçekleştirdiği çalışmasında Gürdal (2013) piyasa ve hiyerarşi kültürünün örtük bilgi paylaşımında daha etkin kültürler olduğunu belirtmektedir. Kutanis ve Mercan (2015) da yaptıkları çalışmada bilgiye bakış açısının ve bilgi paylaşım düzeyinin örgüt kültürü ile ilişkili olduğunu vurgulamaktadır. Erdem ve arkadaşları (2010) da Fırat Üniversitesinde yaptıkları çalışmada baskın örgüt kültürünün hiyerarşi olduğunu vurgulamaktadır. Dolayısıyla örgüt kültürü bilgi paylaşım niyetine etki eden bir unsur olmakla birlikte özelde üniversite gibi kamu kurumlarında bilgi paylaşımının artışı baskın örgüt kültürü olan hiyerarşi kültürünün ne düzeyde çalışanlar tarafindan algılandığı ve yöneticilerin bu kültürü ne kadar aktif şekilde kullandığına bağlı olduğu belirtilebilir. Ayrıca üniversite gibi gelişimi ve değer üretimini temel alan kamu kurumlarında adokrasi kültürü beklenilen yada arzulanan bir tipolojiyken hiyerarşi kültürünün etkisinden ve yapısal sorunlarından bu kurumların kurtulamaması ayrı bir tartışma konusudur. 
Çalışmamızdan elde ettiğimiz diğer bir sonuca göre prosedürel, dağııımsal ve etkileşimsel adalet boyutlarından prosedürel adalet boyutunun üniversite içinde bilgi paylaşım niyetini pozitif yönde etkilediği elde edilen verilere göre tespit edilmiştir. Prosedürel adalete göre; alınan kararlara işgörenleri dahil etmek, var olan kuralı herkese uygulamak, işgörenler tarafından yapılan hataların düzeltilebilme imkanının olması ve karşılaşılacak hatalara karşı tedbirlerin alınması gerekmektedir. Bu özellikler çerçevesinde, kurum içerisinde çalışan personellerin kurum için alınan kararlarda söz sahibi olmaları, onların çevresiyle bilgi paylaşım niyetinde olmalarını sağlayacaktır. Fikirlerini özgürce ifade edebildikleri ortamlar oluşturulabilirse çalışanlar sahip oldukları bilgileri daha kolay paylaşma niyetinde bulunacaktır. Örgüt içerisindeki adalet davranışının mükafat veya ceza noktasında herkese adilane uygulanmasıyla da işgörenler kurum içindeki çalışma arkadaşlarıyla veya üst kademedeki amirleriyle daha kolay bilgi paylaşma niyetinde bulunacaklardır.

Demirel ve Seçkin (2011) ilaç sektöründe çalışan personeller üzerinde yaptıkları çalışmalarında örgütsel adalet boyutlarının tümünün çalışanların sahip oldukları bilgiyi paylaşma yönünde pozitif bir etki oluşturduğunu saptamışlardır. Uludağ ve arkadaşlarının (2018) yaptıkları çalışmaya göre prosedürel ve etkileşimsel adalet algısının bilgi paylaşımına pozitif yönde etki ettiği tespit edilmiştir. Ünlü ve arkadaşlarının (2015) yaptığı çalışmaya göre ise dağıtımsal, prosedürel ve etkileşimsel adalet algıları ile savunmacı sessizlik düzeyleri arasında negatif yönlü, korumacı ve kabullenici sessizlik düzeyleri ile pozitif yönlü bir ilişki olduğunu göstermiştir. Yani korumacı ve kabullenici niyetlerle bilgi paylaşımının yapılmaması da örgütsel adalet algısı ile ilişkilidir. Tüm belirtilen ilişkiler çerçevesinde örgütlerde bilgi paylaşımının önemli bir faktörü olarak örgüt içinde farklı biçimlerde ortaya çıkan adalet algısı gösterilebilir. Çalışmamız kapsamında elde edilen sonuca göre üniversitede çalışan bireylerin bilgi paylaşım niyetlerinde sadece örgütsel kararların ne olduğu ile ilgilenmedikleri aynı zamanda bu kararları belirleyen prosedürlerdeki adalet ile de ilgilendikleri tespit edilmiştir. Dolayısıyla kararlara katılım, şeffaflık, bilgilendirme, fikir alışverişinde bulunma gibi davranışların örgüt içinde hem üst yönetim hem de çalışanlar arasında özendirilmesi bilgi paylaşımını pekiştirmektedir.

Çalışma sonucunda elde ettiğimiz bir diğer sonuca göre bilgi paylaşımının bir davranışa ve tutuma dönüşmesi için öncelikle bilgi paylaşma niyeti bireylerin zihinlerinde pekiştirilmelidir. $\mathrm{Bu}$ noktada örgütte faaliyette bulunan personellerin sahip oldukları bilgiyi başkalarıyla paylaşma davranışının artması için örgüt içindeki bilgi paylaşım niyetini pekiştirici önlemler ve tedbirlerin arttırılması gerekmektedir. Örneğin stratejik veri akışını yönlendirici bir denetçinin olması, verilerin Big Data mantığıyla veritabanlarına kaydedilmesi veya kritik noktalarda şirketine rekabet avantajı kazandırıcı bilgi sağlayan personellerin ödüllendirilmesi gibi uygulamalar hayata geçirilebilir.

Ayrıca, örgüt yöneticileri bilgi paylaşım niyetini ve tutumunu pozitif yönde etkileyecek örgütsel yapıyı kurmak, iletişim ağını ve araçlarını zenginleştirmek ve bilgi paylaşımını örgüt kültürünün bir parçası haline getirmek gibi yaklaşımlar içinde bulunabilir ki içinde bulunduğumuz yüzyıl itibariyle teknolojik gelişimler bunu oldukça kolaylaştırmaktadır

Örgüt yöneticileri ceza veya mükâfatın hak edilmesi zamanında gelişen tüm süreçle alakalı bilgileri örgütteki personellerle paylaşmalıdır ki çalışanlar alınan sonuçların adilliğine güvenebilsinler. Yapılan uygulamaların içeriğine ve sonuçlarına ait bilgiler yöneticiler tarafından personellere aktarılmadığı takdirde çalışanların örgüt içerisindeki yapıyı ve adaleti sorgulamalarına sebebiyet vermektedir. 
Araştırma kapsamında örgüt kültürü ve örgütsel adalet algısının bilgi paylaşımında kritik değişkenler olduğu varsayımıyla hareket edilmiştir. Ancak içinde bulunduğumuz dönemde bilginin elde edilmesi, korunması ve paylaşılması durumlarında teknolojik gelişmelerin önemi yadsınamaz düzeydedir. Dolayısıyla örgüt içinde bilgi paylaşımında teknolojinin kullanımı, iletişim kanallarının bilgi paylaşımına hazır olma durumu, bilgi işleme ve aktarma sürecindeki engeller vb. konular üzerinden de bilgi paylaşımını etkin hale getirecek araştırmalar gerçekleştirebilir.

\section{KAYNAKÇA}

ATALAY C. G. (2010). “Örgütsel Adalet”, D.E. ÖZLER (Der.), Örgütsel Davranışta Güncel Konular. Ekin Basım Yayın, Bursa.

AYAZLAR, G. (2012). “Otel İşletmelerinde Örgütsel Öğrenme ve Bilgi Paylaşımının Hizmet İnovasyon Performansına Etkisi: Kuşadası 5 Yıldızlı Otel İşletmelerinde Bir Araştırma", Doktora Tezi, Adnan Menderes Üniversitesi Sosyal Bilimler Enstitüsü, Aydın.

AYDINTAN, B., GÖKSEL, A. \& BİNGÖL, D. (2010). “Örtülü Bilgi Paylaşım Niyeti Üzerinde Sosyal Sermaye ve Denetim Merkezi Odaklılığının Rolü: Hekimlikte Bir Alan Araştırması", Gazi Üniversitesi İİBF Dergisi, 12(1), 1-26.

BARUTÇUGİL, İ. (2002). Bilgi Yönetimi. Kariyer Yayınları, 2. Basım, İstanbul.

BOCK, G.W., ZMUD, R.W., KIM, Y.G. \& LEE, J.N. (2005). "Behavioral Intention Formation in Knowledge Sharing: Examining the Roles of Extrinsic Motivators, Social-Psychological Forces, and Organizational Climate", MIS quarterly, 29(1), 87111.

CAMERON, K.S. \& FREEMAN, S.J. (1991). "Cultural Congruence, Strength and Type: Relationships to Effectiveness", Research in Organizational Change and Development, Vol.5, 23-58.

CAMERON, K.S. \& QUINN, R.E. (1999). Diagnosing and Changing Organizational Culture, Addison Wesley, USA.

CONNELLY, C.E. \& KELLOWAY, K. E. (2003). "Predictors of Employees' Perceptions of Knowledge Sharing Cultures", Leadership \& Organization Development Journal, 24(5), 294-301.

ÇAKMAK K.Ö. (2005). "Performans değerlendirme Sistemlerinde Örgütsel Adalet Algısı ve Bir Örnek Olay Çalışması”, Yüksek Lisans Tezi, İstanbul Üniversitesi Sosyal Bilimler Enstitüsü, İstanbul.

ÇELİK, V. (2000). Okul Kültürü ve Yönetimi. Pegem Yayıncılık, 2.Basım, Ankara.

DEMİREL, Y. \& YENIÇERİ, Ö. (2007). “Örgüt İçi Bilgi Paylaşımına Yönelik Bireysel Ve Örgütsel Engeller Üzerine Bir Araştırma”, Karamanoğlu Mehmetbey Üniversitesi Sosyal ve Ekonomik Araştırmalar Dergisi, Sayı: 12, 221-234.

DEMİREL, Y. \& SEÇKİN, Z. (2011). “Örgütsel Adaletin Bilgi Paylaşımı Üzerine Etkisi: İlaç Sektörü Çalışanlarına Yönelik Bir Araştırma”, Bilig Dergisi, Sayı:56, 99-119. 
DENISON, D.R. \& SPREITZER, G.M. (1991). “Organizational Culture and Organizational Development: A Competing Values Approach", Research in Organizational Change and Development, Vol.5, 1-21.

DESHPANDE, R., FARLEY, J.U. \& WEBSTER JR., F.E. (1993). "Corporate Culture, Customer Orientation, and Innovativeness in Japanese Firms: A Quadrad Analysis", Journal of Marketing, Vol.57, 23-37.

DINÇER, Ö. (2008). Örgüt Geliştirme Teori Uygulama Ve Teknikleri. Alfa Yayınları, İstanbul.

DIPADOVA, L.N. \& FAERMAN, S.R. (1993). "Using the Competing Values Framework to Facilitate Managerial Understanding Across Levels of Organizational Hierarchy", Human Resource Management, 32(1), 143-174.

DOĞAN, H. (2002). "İşgörenlerin Adalet Algılamalarında Örgüt İçi İletişim Ve Prosedürel Bilgilendirmenin Rolü’, Ege Akademik Bakış Dergisi, 2(2), 71-78.

EKER, G. (2006). “Örgütsel Adalet Algısı Boyutları Ve İş Doyumu Üzerindeki Etkileri”, Yüksek Lisans Tezi, Dokuz Eylül Üniversitesi, Sosyal Bilimler Enstitüsü, İzmir.

ERDEM, R. (2007). “Örgüt Kültürü Tipleri ile Örgütsel Bağlılık Arasındaki İlişki: Elazığ İl Merkezindeki Hastaneler Üzerinde Bir Çalışma”, Eskişehir Osmangazi Üniversitesi İ̇BF Dergisi, 2(2), 63-79.

ERDEM, R., ADIGÜZEL, O. \& KAYA, A. (2010). "Akademik Personelin Kurumlarına İlişkin Algıladıkları ve Tercih Ettikleri Örgüt Kültürü Tipleri”. Erciyes Üniversitesi İ̇BF Dergisi, Sayı: 36, 73-88.

ERDOĞAN, İ. (1994). İşletmelerde Davranış. Beta Yayınları, İstanbul.

EREN, E. (2000). Örgütsel Davranış ve Yönetim Psikolojisi. 6. Baskı, Beta Yayınları, İstanbul.

ERENGÜL, B. (1997). Kültür Sihirbazları. Evrim Yayınları, İstanbul.

GENÇ, N. (1993). "Örgüt Kültürünün Oluşumu ve Bireysel ve örgütsel Davranışlar Üzerindeki Etkisi”, Atatürk Üniversitesi İİBF Dergisi, 10(1-2), 301-302.

GÖK E.E. (2007). “Örgütsel Kültür Bağlamında Örgütsel Vatandaşlık Olgusu Ve Bir Araştırma”, Yüksek Lisans Tezi, Pamukkale Üniversitesi, Sosyal Bilimler Enstitüsü, Denizli.

GÜRDAL, S.A. (2013). “Örgüt Kültürü Ve Bilgi Paylaşımı İlişkisine Yönelik Bir Araştırma”, Yüksek Lisans Tezi, Trakya Üniversitesi, Sosyal Bilimler Enstitüsü, Edirne.

GÜVENÇ, B. (1991). İnsan ve Kültür, Remzi Kitabevi Yayınları, 5. Baskı, İstanbul

HART, S.L. \& QUINN, R.E. (1993). "Roles Executives Play: CEOs, Behavioral Complexity, and Firm Performance", Human Relations, 46(5), 543-574.

IPE, M. (2003). “Knowledge Sharing In Organizations: A Conceptual Framework”, Human Resource Development Review, 2(4), 337-359. 
IŞIK, O., UĞURLUOĞLU, Ö. \& AKBOLAT, M. (2012). "Sağlık Kuruluşlarında Örgütsel Adalet Algılarının Örgütsel Bağlılığa Etkisi”, Doğuş Üniversitesi Dergisi, 13(2), 254265 .

İŞCAN, Ö.F. \& TİMUROĞLU, K. (2007). “Örgüt Kültürünün İş Tatmini Üzerindeki Etkisi ve Bir Uygulama”. Atatürk Üniversitesi Sosyal Bilimler Enstitüsü Dergisi, 21(1), 119135 .

İŞCAN, Ö.F. \& NAKTIYYK, A. (2004). "Çalışanların Örgütsel Bağdaşımlarının Belirleyicileri Olarak Örgütsel Bağlılık ve Örgütsel Adalet Algıları”, Ankara Üniversitesi Siyasal Bilgiler Fakültesi Dergisi, 59(1), 181-201.

KARAGÖZ, Y. (2014). SPSS 21.1 Uygulamalı Biyoistatistik. Nobel Yayınları, Ankara.

KAYALAR M. \& ÖZMUTAF, M. (2007). “Gelişme Yönelimli Kurum Kültürü İle Yöneticinin Yönetsel Tutumları Arasındaki İlişkisellik:100 Büyük Sanayi Kurulusunda Bir Araştırma”, Süleyman Demirel Üniversitesi İİBF Dergisi, 12(3), 163 176.

KAYIŞ, A. (2010). “Güvenilirlik Analizi”., Ş. KALAYCI (Der.), SPPS Uygulamalı Çok Değişkenli İstatistik Teknikleri, 5. Baskı, Asil Yayın Dağıtım, Ankara.

KÖSE, S., TETIKK S. \& ERCAN, C. (2001). “Örgüt Kültürünü Oluşturan Faktörler”, Yönetim ve Ekonomi Dergisi, 7(1), 219-242.

KUTANIS, R.Ö. \& MERCAN, N. (2015). “Bilgi Paylaşım Davranışlarının Örgüt Kültürüyle İlişkisine Yönelik Bir Araştırma”, İş ve İnsan Dergisi, 2(2), 147-155.

LAMBERT, E. (2003).” The Impact of Organizational Justice on Correctional Staff”, Journal of Criminal Justice, 31(2), 155-168.

NIEHOFF, B.P. \& MOORMAN, R.H. (1993). "Justice as a Mediator of the Relationship Between Methods of Monitoring and Organizational Citizenship Behavior", Academy of Management Journal, 36(3), 527-556.

ÖZENLİ, S. (2006). "İşletmelerdeki Örgütsel Kültür Yapısının Takım Anlayışına Etkisi” Yüksek Lisans Tezi, Dumlupınar Üniversitesi, Sosyal Bilimler Enstitüsü, Kütahya.

ÖZKALP, E. \& KIREL, Ç. (2013). Örgütsel Davranış, Ekin Kitabevi Yayınları, Bursa.

PANAYOTOPOULOU, L., BOURANTAS, D. \& PAPALEXANDRİS, N. (2003). "Strategic Human Resource Management and Its Effects on Firm Performance: An Implementation of the Competing Values Framework", International Journal of Human Resource Management, 14(4), 680-699.

TAŞKIRAN, E. (2011). Liderlik ve Örgütsel Sessizlik Arasındaki Etkileşim, Örgütsel Adaletin Rolü, Beta Yayınları, İstanbul.

TYLER, T.R. \& FOLGER, R. (1980). "Distributional and Procedural Aspects of Satisfaction with Citizen-Police Encounters", Basic and Applied Social Psychology, 1(4), 281-292.

ULUDAĞ, O., AKTAŞ, İ. \& ÖZGİT, H. (2018). Eğitim Çalışanlarının Örgütsel Adalet Algılarının ve Örgüt Kültürünün Bilgi Paylaşımı Üzerindeki Etkileri: Örgüt 
Kültürünün Aracı Rolü. Hacettepe Üniversitesi Eğitim Fakültesi Dergisi, doi: 10.16986/HUJE.2018037423.

ÜNLÜ, Y., HAMEDOĞLU, M.A. \& YAMAN, E. (2015). “Öğretmenlerin Örgütsel Adalet Algıları ve Örgütsel Sessizlik Düzeyleri Arasındaki İlişki”, Sakarya University Journal of Education, 5(2), 140-157.

VAN DEN HOOFF, B. \& DE RIDDER, J.A. (2004). "Knowledge Sharing in Context: The Influence of Organizational Commitment, Communication Climate and CMC Use on Knowledge Sharing", Journal of Knowledge Management, 8(6), 117-130.

YANIK, O. (2014). “Ahlaki Liderliğin Çalışanların İş Tatminine, Örgütsel Bağlılığa Ve İşten Ayrılma Niyetine Etkisi: Örgütsel Güven Ve Örgütsel Adalet Algısının Aracı Rolü” Doktora Tezi, Atatürk Üniversitesi, Sosyal Bilimler Enstitüsü, Erzurum.

YILDIRIM, F. (2002). "Çalışma Yaşamında Örgüte Bağl1lık ve Örgütsel Adalet İlişkisi”,, Doktora Tezi, Ankara Üniversitesi, Sosyal Bilimler Enstitüsü, Ankara.

YILDIRIM, F. (2007). “İş Doyumu ile Örgütsel Adalet İlişkisi”, Ankara Üniversitesi SBF Dergisi, 62(1), 253-278.

YILMAZ G. (2004). “İnsan Kaynakları Uygulamalarına İlişkin Örgütsel Adalet Algısının Çalışanların Tutum Ve Davranışları Üzerindeki Etkisi”, Doktora Tezi, İstanbul Üniversitesi, Sosyal Bilimler Enstitüsü, İstanbul. 